[Original]

\title{
Influences of Occupational Burnout and Personality on Lipid Peroxidation Among Nurses in Shahroud City, Iran
}

\author{
Jamal Biganeh $^{1}$, Jamileh Abolghasemi ${ }^{2}$, Iraj Alimohammadi ${ }^{3}$, Hossein Ebrahimi ${ }^{3}$, Behzadipour Davoud ${ }^{4}$, \\ Majid Bagheri Hosseinabadi ${ }^{1}$ and Azadeh AshtARINEZHAD ${ }^{3 *}$ \\ ${ }^{1}$ School of Public Health, Shahroud University of Medical Sciences, Hafte Tir Square, Shahroud, Iran \\ 2 Department of Biostatistics, School of Public Health, Iran University of Medical Sciences, Shahid Hemmat Highway, \\ Tehran, 1449614535 Iran \\ ${ }^{3}$ Department of Occupational Health Engineering, School of Public Health, Iran University of Medical Sciences, \\ Hemmat Highway Tehran, 1449614535 Iran \\ ${ }^{4}$ Department of Occupational Health Engineering, School of Public Health, Tarbiat Modaress University, Tehran, \\ Jamal AleAmad, Nasr, 14115-111 Iran
}

\begin{abstract}
Considering the relationship between occupational burnout and oxidative stress, identifying the factors that affect occupational burnout, such as recognizing individual characteristics, would be beneficial for implementing strategies to reduce oxidative stress levels. This study was conducted on 92 nurses from a hospital in Shahroud, a city in northeastern Iran, who were chosen at random. The data was collected through the Demographic Questionnaire, Maslach Burnout Inventory and Personality Factors Inventory. Each participant's serum markers of oxidative stress were also measured. Total antioxidant capacity (TAC) and neuroticism were found to have a negative relationship in this study. Furthermore, marital status, the ward where nurses work, the type of contract, emotional exhaustion, and depersonalization were all found to be significant predictors of malondialdehyde (MDA). Neuroticism, emotional exhaustion, and depersonalization were the most important predictors of oxidative stress levels. The results of this study suggest that some approaches to reducing oxidative stress can be implemented by identifying the factors influencing occupational burnout and also by recognizing individuals' personality traits.
\end{abstract}

Keywords : burnout, personality, malondialdehyde, total antioxidant capacity, nurse.

(Received February 15, 2021, accepted August 30, 2021)

\section{Introduction}

Occupational burnout is a common problem in today's workplaces, causing cost and loss for both employers and employees. Job burnout is defined as emotional exhaustion, depersonalization, and decreased personal accomplishment, and it is a long-term reaction to workplace stressors $[1,2]$. Because these potential hazards are prevalent in the workplaces of health care workers and nurses, it is worthwhile to pay more attention to them.

According to some studies, occupational burnout can cause physical illnesses, psychological problems, cardiovascular diseases, musculoskeletal disorders, obesity, insomnia, depression, anxiety, increased alcohol consumption, and drug use, as well as poor service

*Corresponding Author: Azadeh Ashtarinezhad, Department of Occupational Health Engineering, School of Public Health, Iran University of Medical Sciences, Hemmat Highway, Iran University of Medical Sciences, Tehran, Iran. Tel:+982186704754, Fax:+9821-88622707, E-mail: 
quality in the healthcare system [3, 4]. Burnout also leads to employee absenteeism, quitting and leaving, a high rate of turnover, job dissatisfaction, and a lack of employee commitment, as well as an increase in service costs [5-7].

Although a stressful workplace can contribute significantly to occupational burnout, understanding individual characteristics and differences may aid in determining why certain people are more susceptible to occupational burnout $[8,9]$. Several recent studies have highlighted the importance of psychological variables. Personal characteristics have been considered as one of the most important factors in preventing or causing a disorder $[10,11]$. Personality traits can also have an impact on suicide, depression, drug use, stress, job burnout, and work-related mistakes and errors in doctors and health care personnel (HCP) [12].

Recent research using the "big-five personality factors" pinpointed a relationship between personal characteristics and occupational burnout, and this model, which describes personality in five basic factors, is one of the most commonly used characteristic evaluation theories $[13,14]$. Other studies have emphasized the significance of the link between occupational burnout and oxidative stress [15-17].

Oxidative stress is defined as an imbalance between free radicals and antioxidants in cells [18]. When an employee is exposed to occupational stress, the concentration of reactive oxygen species (ROS) rises and it causes serious damage to cells and their membrane structure, as well as apoptosis induction $[16,19]$. ROS can also induce DNA mutation [20], changes in the structure and function of proteins, peroxidation and destruction of the lipid membrane of cell [21, 22], cause cancer [23], neurological disorders [24], cardiovascular diseases [25], and diabetes [26], and accelerate the aging process [27].

Total antioxidant capacity (TAC) is used to express oxidative stress levels in the enzymatic portion. Lipid peroxidation is one of the most common sources of free radicals that directly target and damage membranes and it also makes some other by-products such as Malondialdehyde (MDA). This compound is one the most important products of lipid peroxidation, and measuring its level in the body can be used to estimate the extent of lipid peroxidation. The purpose of this study was to determine the effect of burnout, personality factors, and oxidative stress on nurses working in a hospital in Shahroud City, Iran.

\section{Methods}

\section{Study Population and Sample Size}

This descriptive-analytical (cross-sectional) study was conducted on undergraduate and postgraduate nurses from an educational hospital in Shahroud. These graduate nurses were assigned by their university to work in the city hospital. A nursing academic degree and at least two years of work experience were required for participation in this study. Smoking, using antioxidant supplements (at least two weeks before blood sampling), and working in oncology and chemotherapy wards were all exclusion criteria. Since chemotherapy drugs, ionizing radiation, and cigarette smoke can all influence the body's antioxidant system, these samples were excluded from this study. Cigarette smoke contains a variety of oxidants that have the potential to generate reactive oxygen and nitrogen. Chronic oxidative stress is a significant byproduct of the late post-radiation phenomenon, causing responses caused by ROS generation by the electron transport chain (ETC) and the cytoplasmic NADPH oxidases. The effect of chemotherapy-induced oxidative stress on antineoplastic efficacy and the role of reactive oxygen species (ROS) in drug-induced apoptosis are well established [28-31].

All the nurses working in various wards of the hospital were included in the study program to ensure as much diversity in participants as possible (except for the exemptions mentioned before). The error value was considered as 0.05 in the calculation of the sample size. Due to the study objectives, the Cochran formula was used to estimate the sample size, where $\sigma^{2}$ variance of 10.38 was extracted from previous studies and "d" as the accuracy rate was 2.3 [16]. Finally, the minimum sample size was calculated as 78 subjects. Considering the $15 \%$ sample loss, the sample size was determined as 92 subjects. A list of nurses based on pre-defined inclusion and exclusion criteria was obtained from hospital personnel files and contract documents. Then, using the stratified random sampling method, eligible individuals were chosen for partici- 
pation in this study based solely on their IDs rather than their names.

\section{Ethical Considerations}

The present study was approved by the Ethics Committee of Iran University of Medical Sciences, with the code of ethics of IR.IUMS.REC 1395.9411139004. The volunteers signed the informed consent form. The participants were assured that their information would be kept private and used only for research purposes. An in-charge researcher was present during the questionnaire responses to provide any possible explanations if there were any questions or ambiguity in the questionnaires. All volunteers had the option to withdraw from the study at any point during the study with no consequences.

\section{Data Gathering Tools}

\section{Data Collection}

The results of this study were obtained from three questionnaires, which included demographic-organizational, occupational burnout, and personality factors, as well as a blood study of the participants. All participants were given a thorough description of the study's goals at the beginning, and their consent was documented.

\section{Demographic - Organizational Questionnaire}

All the completed questionnaires, as well as the participants' age, gender, marital status, job status, working ward, level of education, work experience, type of work-shift (day, night, or rotating), height, and weight for BMI calculation, were classified as confidential information.

\section{Occupational Burnout}

The Maslach Burnout Inventory (MBI) was developed in 1981 to determine the level of occupational burnout among nurses. The MBI examines occupational burnout in terms of the three dimensions of emotional exhaustion (EE), depersonalization (DE), and personal accomplishment (PA) in individuals. The questionnaire consists of 22 questions, including nine questions related to emotional exhaustion, eight questions related to the reduction of personal accomplishment, and five questions about depersonalization. This questionnaire's measurement scale is a Seven-Likert scale (ranging from 0 to 6 ) and the score is based on the frequency of people's feelings on each topic. In this study, the cut-off point was classified into three parts $(33.3 \%$ and $66.6 \%)$ to categorize the participants into low, moderate, or high levels of Burnout [32]. The validity and reliability of this questionnaire were approved by Filian in Iran in 1992. According to his reports, the coefficient of reliability by the test-retest method was reported as 0.78 [33].

\section{Personality factors}

The personality factors assessment questionnaire known as NEO-FFI (NEO-Five Factor Inventory), which was designed by Costa and Maccary in 1992, was used in this study [34]. The questionnaire consists of the five factors of extraversion, agreeableness, conscientiousness, neuroticism, and openness to experience. In the 60-question version of this questionnaire, each factor has 12 questions and each item's measurement scale is a five-option Likert scale of totally disagree, disagree, neutral, agree, and fully agree. A short version of this questionnaire was used for this study. In their study, Ghanei et al examined the internal correlation between the dimensions of this questionnaire. By using Cronbach's alpha, they reported that the correlation between these dimensions for neuroticism, extraversion, agreeableness, adaptation, and conscientiousness was $0.67,0.72,0.68,0.62$, and 0.81 , respectively [35].

\section{Collecting Blood Samples}

Malondialdehyde levels and total antioxidant levels were determined using blood serum samples from participants. Participants were asked to fast (not eat) for at least 8 hours before blood sampling, and then 2 $\mathrm{m} l$ of their left ventricle blood was collected and samples were directly transferred to the laboratory. After centrifuging the samples at 3,000 rpm for 10 minutes, the extracted serums were stored at $-80^{\circ} \mathrm{C}$ for further analysis.

\section{Samples Analysis}

\subsection{TAC Biomarker Analysis}

A commercial kit provided by ZellBio Company, Germany (ZellBio GmbH, Germany) was used to ana- 
lyze the TAC biomarker, and the test procedure was carried out according to the instructions provided by the Company. These kits use the colorimetric method and are based on the reduction of $\mathrm{Fe}(3+)$ to $\mathrm{Fe}(2+)$ by antioxidants, which are coupled with a suitable chromogen (dye), and the result creates a color that can be read at the wavelength of $490 \mathrm{~nm}$ (by ELISA reader, stat fax 2100).

\subsection{MDA Biomarker Analysis}

A commercial kit provided by ZellBio Company, Germany (ZellBio $\mathrm{GmbH}$, Germany) was used for MDA biomarker analysis, and the steps of the test were carried out according to the Company's instructions. In this kit, malondialdehyde reacts with Thiobarbituric acid (TBA) at a high temperature and makes a pink color, which can be read by the colorimetric method at the wavelength of 530-540 nm (by ELISA reader, stat fax 2100).

\section{Statistical Analysis}

The descriptive statistics including frequency, mean and standard deviation were used to analyze demographic and organizational data. Occupational burnout dimensions and personal factors were considered as independent variables, and oxidative stress level was accounted as a dependent variable. The normality of the data was verified and confirmed in the first step using the Kolmogorov-Smirnov test. The ANOVA test, independent t-test, and the correlation coefficient were used for data analysis. The relationships between occupational burnout dimensions, personality factors, and oxidative stress levels were analyzed by using the Pearson correlation coefficient test. Multiple linear regression was used to determine the predictive variables of oxidative stress levels. All calculations and statistical analyzes were performed using SPSS software (Version 24, IBM Corp., Armonk, NY) at an error rate of 0.05 .

\section{Results}

In this study, the coefficients of reliability for each dimension of depersonalization, emotional exhaustion, and reduced personal accomplishment were calculated as $0.76,0.81$, and 0.70 , respectively, and the obtained results demonstrated the questionnaire's stability and reliability. The coefficients of reliability for each dimension of neuroticism, extraversion, agreeableness, adaptation, and conscientiousness were calculated as $0.69,0.82,0.67,0.71$, and 0.72 , respectively, showing the stability and reliability of the questionnaire.

Table 1 shows the mean values of the three dimensions of occupational burnout, as well as the mean level of TAC and MDA, based on the demographic variables. The majority of the participants $(85.9 \%)$ were female, and $54.3 \%$ of them had less than ten years of work experience. Around three-quarters of the nurses (75\%) were married, and $66.3 \%$ of all the participants were working in rotating shift work.

Figure 1 shows the percentage distribution of occupational burnout levels for the hospital nurses. In the personal accomplishment dimension, the highest number of nurses were at the high level of occupational burnout (59 nurses, 64.1\%), while in emotional exhaustion $38 \%$ of the subjects were at a moderate level of burnout, and in depersonalization $63 \%$ of the subjects were in a low level of burnout.

Relationship between dimensions of occupational burnout, personality factors, and oxidative stress

Table 2 shows the relationship between job burnout, personality factors, and oxidative stress (using the Pearson Test). Among all the burnout dimensions, emotional exhaustion and oxidative stress demonstrated a remarkable relationship with other dimensions of personality factors (except for "openness to experience"). For neuroticism, extroversion, and agreeableness, the $P$-value measured 0.05 , and for conscientiousness, TAC, and MDA, the $P$-Value measured 0.01. The TAC biomarker had a significant relationship with dimensions of emotional exhaustion, depersonalization, personal accomplishment, neuroticism, and conscientiousness. The MDA biomarker was found to have a meaningful relationship with the dimensions of emotional exhaustion and depersonalization only. The correlation coefficients for emotional exhaustion and depersonalization measured $r=0.499$, and for the personal accomplishment and extroversion measured $r=0.476$.

The multiple linear regression model was used to 
Table 1. Demographic and organizational variables of nurses

\begin{tabular}{|c|c|c|c|c|c|c|}
\hline \multirow{2}{*}{ Variables } & \multirow{2}{*}{$\begin{array}{r}\text { Frequency } \\
(\%)\end{array}$} & \multicolumn{3}{|l|}{ Burnout } & \multirow{2}{*}{ TAC } & \multirow{2}{*}{ MDA } \\
\hline & & $\overline{\mathrm{EE}}$ & $\mathrm{DE}$ & PA & & \\
\hline \multicolumn{7}{|l|}{ Age (y) } \\
\hline$\leq 30$ & $30(32.6)$ & $20.30 \pm 7.78$ & $5.6 \pm 3.97$ & $27.13 \pm 6.68$ & $0.55 \pm 0.14$ & $2.80 \pm 1.89$ \\
\hline $31-39$ & $32(34.8)$ & $20.90 \pm 11.18$ & $5.46 \pm 4.67$ & $29.68 \pm 6.22$ & $0.62 \pm 0.19$ & $2.69 \pm 1.76$ \\
\hline$\geq 40$ & $30(32.6)$ & $18.13 \pm 10.80$ & $5.33 \pm 3.88$ & $32.26 \pm 8.78$ & $0.79 \pm 0.42$ & $2.91 \pm 1.80$ \\
\hline$P$-Value & & 0.540 & 0.970 & 0.028 & 0.005 & 0.893 \\
\hline \multicolumn{7}{|l|}{ Gender } \\
\hline Female & $79(85.9)$ & $16.53 \pm 10.17$ & $4.53 \pm 3.95$ & $30.61 \pm 8.34$ & $0.74 \pm 0.34$ & $2.49 \pm 1.61$ \\
\hline Male & $13(14.1)$ & $20.27 \pm 9.95$ & $5.62 \pm 4.19$ & $29.54 \pm 7.40$ & $0.63 \pm 0.28$ & $2.85 \pm 1.83$ \\
\hline$P$-Value & & 0.214 & 0.388 & 0.636 & 0.225 & 0.507 \\
\hline \multicolumn{7}{|l|}{ Experience (y) } \\
\hline$\leq 10$ & $50(54.3)$ & $18.98 \pm 8.33$ & $5.62 \pm 4.54$ & $28.76 \pm 7.06$ & $0.58 \pm 0.20$ & $2.59 \pm 1.72$ \\
\hline $11-20$ & $30(32.6)$ & $21.76 \pm 11.06$ & $5.13 \pm 3.48$ & $29.23 \pm 7.62$ & $0.78 \pm 0.39$ & $2.91 \pm 2.02$ \\
\hline$\geq 21$ & $12(13)$ & $17.91 \pm 13.46$ & $5.66 \pm 4.31$ & $34.75 \pm 7.61$ & $0.60 \pm 0.23$ & $2.97 \pm 1.68$ \\
\hline$P$-Value & & 0.389 & 0.868 & 0.040 & 0.009 & 0.820 \\
\hline \multicolumn{7}{|l|}{ Marital status } \\
\hline Single & $23(25)$ & $20.60 \pm 9.54$ & $6.34 \pm 4.56$ & $27.82 \pm 6.45$ & $0.57 \pm 0.22$ & $2.16 \pm 0.45$ \\
\hline Married & $69(75)$ & $19.46 \pm 10.20$ & $5.17 \pm 4.00$ & $30.31 \pm 7.76$ & $0.68 \pm 0.31$ & $1.58 \pm 0.19$ \\
\hline$P$-Value & & 0.638 & 0.243 & 0.169 & 0.147 & 0.007 \\
\hline \multicolumn{7}{|l|}{ Employment Status } \\
\hline Contract & $31(33.7)$ & $17.70 \pm 9.23$ & $4.96 \pm 4.09$ & $30.77 \pm 7.53$ & $0.67 \pm 0.30$ & $2.33 \pm 1.53$ \\
\hline Permanent & $61(66.3)$ & $20.78 \pm 10.32$ & $5.72 \pm 4.20$ & $29.14 \pm 7.49$ & $0.64 \pm 0.29$ & $3.04 \pm 1.89$ \\
\hline$P$-Value & & 0.165 & 0.415 & 0.329 & 0.721 & 0.077 \\
\hline \multicolumn{7}{|l|}{ Body Mass Index $\left(\mathrm{kg} / \mathrm{m}^{2}\right)$} \\
\hline Underweight & $6(6.5)$ & $15.16 \pm 8.75$ & $4.50 \pm 3.27$ & $31.16 \pm 8.63$ & $0.44 \pm 0.10$ & $3.15 \pm 1.91$ \\
\hline Normal & $51(55.4)$ & $22.15 \pm 10.36$ & $5.68 \pm 4.63$ & $28.41 \pm 6.75$ & $0.61 \pm 0.25$ & $2.75 \pm 1.85$ \\
\hline Pre-obesity & $29(31.5)$ & $16.17 \pm 9.02$ & $5.13 \pm 3.50$ & $29.75 \pm 7.69$ & $0.71 \pm 0.31$ & $3.00 \pm 1.73$ \\
\hline Obesity & $6(6.5)$ & $21.16 \pm 7.88$ & $6.16 \pm 4.26$ & $38.83 \pm 6.64$ & $0.93 \pm 0.40$ & $1.92 \pm 1.77$ \\
\hline$P$-Value & & 0.043 & 0.850 & 0.012 & 0.010 & 0.569 \\
\hline \multicolumn{7}{|l|}{ Education level } \\
\hline Diploma and Bachelor & $86(93.5)$ & $19.63 \pm 9.90$ & $5.43 \pm 4.14$ & $29.59 \pm 7.61$ & $0.65 \pm 0.29$ & $2.74 \pm 1.82$ \\
\hline Master of sciences & $6(6.5)$ & $21.33 \pm 12.51$ & $6.00 \pm 4.81$ & $31.16 \pm 6.08$ & $0.68 \pm 0.38$ & $3.64 \pm 1.35$ \\
\hline$P$-Value & & 0.691 & 0.748 & 0.622 & 0.801 & 0.241 \\
\hline \multicolumn{7}{|l|}{ Shift work } \\
\hline Rotate & $61(66.3)$ & $18.81 \pm 9.90$ & $5.59 \pm 4.40$ & $29.70 \pm 7.33$ & $0.62 \pm 0.24$ & $2.98 \pm 1.73$ \\
\hline Fix & $31(33.7)$ & $21.58 \pm 10.16$ & $5.22 \pm 3.68$ & $30.25 \pm 7.92$ & $0.72 \pm 0.37$ & $2.44 \pm 1.92$ \\
\hline$P$-Value & & 0.214 & 0.694 & 0.611 & 0.113 & 0.172 \\
\hline \multicolumn{7}{|l|}{ Ward } \\
\hline General & $52(56.5)$ & $16.38 \pm 9.12$ & $3.84 \pm 2.32$ & $33.15 \pm 6.82$ & $0.68 \pm 0.33$ & $2.38 \pm 1.79$ \\
\hline Surgery & $16(17.4)$ & $22.64 \pm 9.14$ & $5.64 \pm 3.74$ & $30.64 \pm 5.95$ & $0.58 \pm 0.24$ & $3.53 \pm 1.94$ \\
\hline Critical Units & $11(12)$ & $18.64 \pm 9.56$ & $5.24 \pm 3.24$ & $29.64 \pm 7.72$ & $0.63 \pm 0.14$ & $2.79 \pm 1.48$ \\
\hline Emergency & $13(14.1)$ & $23.68 \pm 9.22$ & $7.31 \pm 2.15$ & $26.52 \pm 7.54$ & $0.68 \pm 0.28$ & $3.57 \pm 1.55$ \\
\hline$P$-Value & & 0.148 & 0.158 & 0.130 & 0.707 & 0.050 \\
\hline
\end{tabular}

TAC: Total antioxidant capacity, MDA: Malondialdehyde, EE: emotional exhaustion, DE: depersonalization, PA: personal acomplishment 


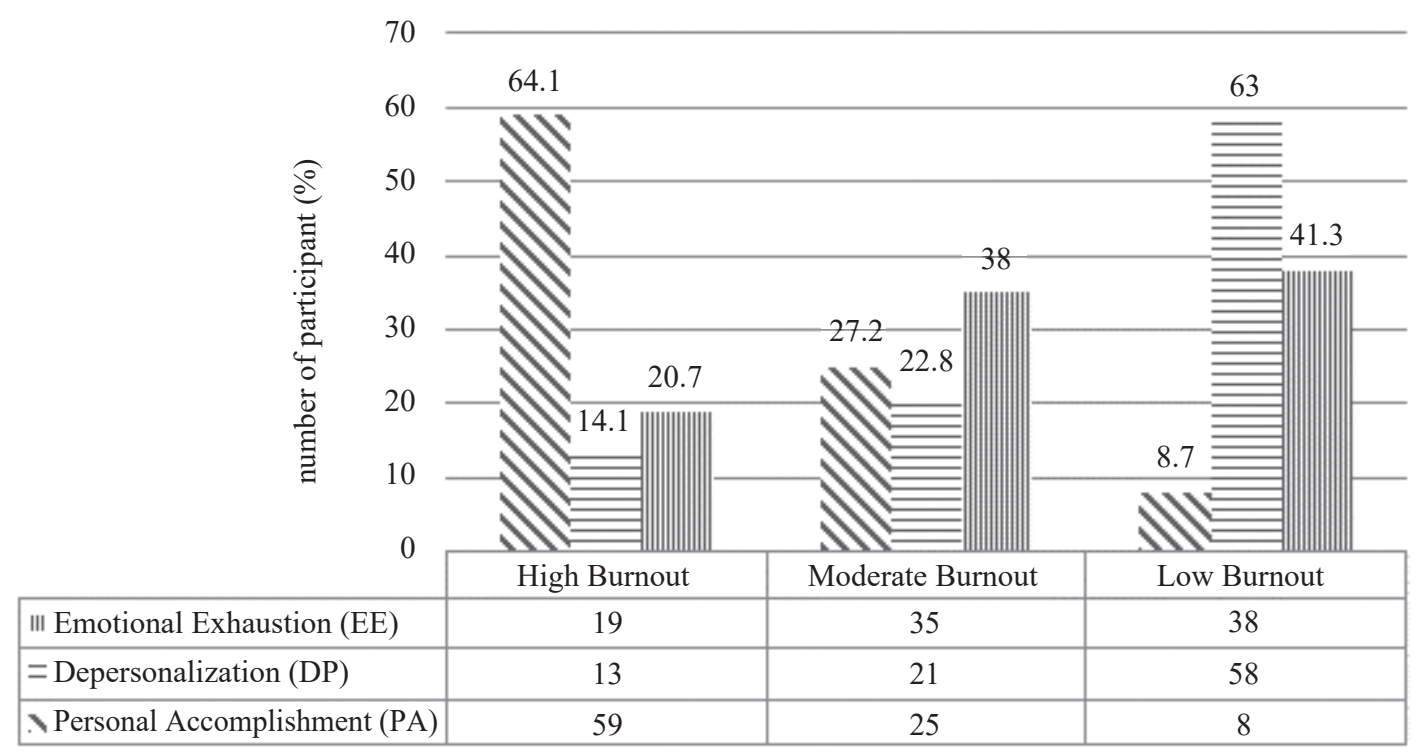

Figure 1. Distribution of occupational burnout levels reported for the dimensions of emotional exhaustion, depersonalization, and personal accomplishment.

Table 2. Correlation Coefficient between different dimensions of occupational burnout, personal factors, TAC, and MDA

\begin{tabular}{|c|c|c|c|c|c|c|c|c|c|}
\hline \multirow[t]{2}{*}{ Variables } & \multicolumn{9}{|l|}{ Items } \\
\hline & 1 & 2 & 3 & 4 & 5 & 6 & 7 & 8 & 9 \\
\hline 1-Emotional Exhaustion & 1 & & & & & & & & \\
\hline 2-Depersonalization & $0.499 * *$ & 1 & & & & & & & \\
\hline 3-Personal Accomplishment & $-0.361 * *$ & $-0.292 * *$ & 1 & & & & & & \\
\hline 4- Neuroticism & $0.366 * *$ & $0.235^{*}$ & $-0.307 * *$ & 1 & & & & & \\
\hline 5- Extraversion & $-0.292 * *$ & -0.109 & $0.476^{* *}$ & -0.134 & 1 & & & & \\
\hline 6- Openness to experience & -0.004 & 0.051 & 0.077 & $0.220 *$ & 0.157 & 1 & & & \\
\hline 7- Agreeableness & $0.284 * *$ & 0.195 & -0.128 & $0.284 * *$ & 0.091 & 0.033 & 1 & & \\
\hline 8- Conscientiousness & $-0.213^{*}$ & 0.017 & $0.220^{*}$ & $-0.243^{*}$ & $0.363 * *$ & $0.224 *$ & 0.112 & 1 & \\
\hline 9- TAC & $-0.243^{*}$ & $-0.222 *$ & $0.205^{*}$ & $-0.323 * *$ & 0.150 & -0.047 & -0.044 & $0.243 *$ & 1 \\
\hline 10-MDA & $0.214 *$ & $0.275 * *$ & -0.201 & 0.075 & -0.009 & -0.014 & -0.058 & -0.005 & -0.182 \\
\hline
\end{tabular}

TAC: Total antioxidant capacity, MDA: Malondialdehyde

identify the most effective predictors of oxidative stress biomarkers (Table 3). Firstly, by using the single regression analysis, the following were used for the multiple linear regression model: all the variables of age, type of work shift, marital status, duration of work experience, MBI; all the dimensions of occupational burnout; all the dimensions of personality factors; MDA level to predict the TAC, working shift, marital status, hospital ward, type of contract; all three dimensions of job burnout; and the TAC levels for predicting MDA with a significance level less than 0.2.
The variables less than 0.2 were entered into the model of single regression tests, and age, work experience, neuroticism, and TAC were the most effective factors among all the studied variables. These results suggest that the most important predictors of MDA concentration were marital status, hospital section, type of contract, emotional exhaustion, and depersonalization.

\section{Discussion}

Nursing is one of the most important occupations 
Table 3. Final fitted multiple linear regression for predictive factors for TAC and MDA

\begin{tabular}{|c|c|c|c|c|c|}
\hline \multicolumn{2}{|l|}{ Variables } & $\mathrm{B}$ & $\mathrm{CI}$ & $P$-Value & $\mathrm{R} 2$ \\
\hline \multicolumn{6}{|l|}{ TAC } \\
\hline Age & $40 \leq$ & 0.106 & $0.172-0.439$ & 0.001 & \multirow[t]{5}{*}{0.299} \\
\hline Experience & $11-20$ & 0.287 & $0.105-0.468$ & 0.002 & \\
\hline BMI & Obesity & 0.192 & $-0.018-0.401$ & 0.072 & \\
\hline Neuroticism & & -0.012 & $-0.021-(-0.003)$ & 0.010 & \\
\hline MDA & & -0.03 & $-0.002-0.058$ & 0.036 & \\
\hline \multicolumn{6}{|l|}{ MDA } \\
\hline Marital status & & -1.084 & $-1.86-(-0.299)$ & 0.007 & \multirow[t]{5}{*}{0.203} \\
\hline Ward & Emergency & 1.353 & $0.354-2.351$ & 0.009 & \\
\hline \multicolumn{2}{|c|}{ Employment Status } & 0.487 & $0.120-0.854$ & 0.010 & \\
\hline \multicolumn{2}{|c|}{ Emotional Exhaustion } & 0.110 & $0.010-0.097$ & 0.044 & \\
\hline \multicolumn{2}{|c|}{ Depersonalization } & 0.114 & $0.031-0.196$ & 0.008 & \\
\hline
\end{tabular}

TAC: Total antioxidant capacity, MDA: Malondialdehyde, BMI: Body mass index

in a healthcare system, and to provide high-quality services, HCP, particularly nurses, must be in good mental and physical health. Nursing shortages are a major concern for many healthcare systems today. Job burnout, as an effective factor, can lead to a lack of commitment and leave; however, individual differences play a significant role in burnout, and chronic exposure to burnout may increase oxidative stress, which can lead to other problems.

\section{Burnout dimensions}

According to the findings of this study, $38 \%$ and $20.7 \%$ of the nurses who took part in it experienced moderate and high levels of emotional exhaustion, respectively. Moreover, $14.1 \%$ of nurses reported a high level of depersonalization, while $64.1 \%$ reported a high level of personal accomplishment. Hayes et al (2015) researched 417 nurses from the hemodialysis departments of hospitals in Australia and New Zealand, and $52.2 \%$ of nurses in that research reported high levels of emotional exhaustion, while $53 \%$ of them had a high level of depersonalization and $58 \%$ of them reported a low level of personal accomplishment [36].

The findings of that study revealed that when nurses see their patients' health improve as a result of their efforts, it creates great incentives for them, and as a result, they are less vulnerable to workplace stressors. Emotional exhaustion, neuroticism dimensions, and agreeableness were discovered to have a direct and significant relationship. In contrast, a significant negative relationship between extraversion and conscientiousness was observed. De la Fuente-Solana EI et al (2017) also reported a meaningful relationship between emotional exhaustion and all dimensions of the personality factors. In their study, the correlation coefficients for neuroticism, extroversion, openness to experience, agreeableness, and conscientiousness were reported as $0.472,-0.293,-0.276,-0.380$, and -0.343 , respectively [37]. In agreement with that study, Jahanbakhsh et al (2009) found a significant relationship in their research between emotional exhaustion and neuroticism, extroversion, and agreeableness [38], while Geuens et al (2017) only reported a significant relationship between emotional exhaustion and neuroticism ( $P$-value $<0.001, \beta=0.618$ ) [39]. People who scored high on the neuroticism dimension tended to exaggerate the severity of problems. These individuals displayed negative emotions (such as despair and depression), and their level of burnout was higher. Extroverts, on the other hand, had a high level of selfconfidence, were often active, and had positive emotions, resulting in less emotional exhaustion.

\section{Burnout and Personality factors}

Depersonalization and neuroticism were found to have a significant relationship in this study. Geuens et al (2017) discovered a significant relationship between depersonalization and dimensions of neuroti- 
cism and conscientiousness [39]. Using the multiple linear regression test, Cañadas-De la Fuente GA et al (2015) observed that, in addition to neuroticism and agreeableness, extraversion also had a meaningful relationship with depersonalization [13].

This study discovered that neuroticism has a remarkable inverse relationship with personal accomplishment ( $P$-value $0.01, r=-0.307)$ and a meaningful direct relationship with extroversion and conscientiousness $(P<0.05, r=0.220$ and $P$-value $<0.01, r=$ 0.476 , respectively). Cañadas-De la Fuente GA et al (2015) and De la Fuente-Solana EI et al (2017) found a significant relationship between personal accomplishment and all dimensions of personality factors in their studies [13, 37]. Nater et al hypothesized in their study that having a high level of conscientiousness can lead people to be more organized in their daily life, which results in more motivation and energy and allows them to face daily challenges better [40].

According to the findings of this study, personality factors have a major impact on the dimensions of occupational burnout. Extraversion and conscientiousness, in general, can help to prevent the development of burnout. Furthermore, extraversion played the most important role in the relationship between the three dimensions of personal factors and occupational burnout. In this regard, customizing interventions to individual differences may aid in reducing job burnout.

\section{Correlation between burnout, personal factors, and oxidative stress}

This study demonstrated that age can be one of the predictor variables of TAC level $(P$-value $<0.001, \beta=$ $0.106)$, and people over the age of 40 had a higher TAC level than those under the age of 30. Demirbag et al (2005) discovered a significant relationship between age and TAC level in males in their study $(P$-value $=$ $0.030, \beta=0.262$ ), and they suggested that age can be used as an independent predictor of TAC [41]. It has been hypothesized that the capacity of the antioxidant system (such as glutathione) is preserved until the age of 45, and it gradually declines after that [42]. In the present study, work experience was also found to have a significant relationship with TAC values. TAC values were higher in individuals with more work experience than in those with less work experience. Al- though in Sharifian et al's (2005) study TAC values decreased with increasing age [43], the small sample size $(n=44)$, the high standard deviation and the mean age of the participants $(36.75,10.18)$ could have been responsible for the unexpected results. Ranjbar et al (2016), on the other hand, discovered no significant relationship between the TAC biomarker and work experience and admitted that this was due to the small sample size and the participants' short work experience (less than 10 years), which resulted in unexpected and insignificant results [44]. The concentration of oxidative agents naturally rises with age, resulting in DNA and protein degradation $[45,46]$. As a result, the concentration of antioxidant biomarkers is expected to rise and it has been reported that some antioxidants are at their highest levels among the cut-off age groups of 20 to 29 [15].

In this study, it was discovered that neuroticism and TAC values have a significant negative relationship. Previous studies have shown that neuroticism, as a tendency to experience negative consequences, causes instability and increases stress levels, both of which are linked to negative health outcomes and diseases $[47,48]$. In a study conducted by Matsushita et al (2010), a significant positive relationship was found between neuroticism and oxidative damage in nonsmoking students [49].

\section{Predictive factors for oxidative stress}

Married nurses had lower levels of MDA than single nurses, according to the findings of this study. Casado et al (2006) found significant differences in MDA levels between single and married groups of 32 nurses (seven men and 25 women) in intensive care units [15]. However, no significant relationship was found between MDA levels and the marital status of the participants in a study conducted by Casado et al (2014) on 70 emergency personnel [50]. According to the findings of the present study, married people had less burnout than single people (Table 1), which could explain their low MDA levels. The findings of this study revealed that nurses working in the emergency ward had higher MDA levels than nurses working in the hospital's general wards. Because emergency department nurses have a higher workload and, on the other hand, are under more pressure due to contact 
with patients' families and relatives, burnout increases among them. Moshtagh et al reported that $76.7 \%$ of participants in their study experienced moderate to high levels of burnout [51].

The level of MDA in this study had a significant relationship with two dimensions of burnout: emotional exhaustion and depersonalization. Given that emotional exhaustion and depersonalization in nurses of the emergency department had the highest mean values, we can conclude that it is one of the most important factors in the higher MDA level among nurses of the emergency ward, and this can be due to a high level of burnout in this ward. In this regard, López et al (2005) found that the rate of burnout among emergency department nurses is high in the dimensions of emotional exhaustion and depersonalization but low in the dimension of personal accomplishment [52].

Nurses with an official long-term contract had higher MDA levels than those with a short-term contract, according to the current study ( $P$-value $<0.01, \beta=$ 0.487). Mehafarid et al (2015) discovered that formal and long-term contracted nurses were more likely to experience burnout than short-term or informal contracted nurses. This result could be due to formally contracted nurses having increased responsibilities and expectations [53]. Similar findings were also reported by Zhang et al (2014) [54]. The reasons for these results could be that formal nurses are mostly headmasters (matrons) and are in charge of more important and stressful duties, so they are expected to perform better than other nurses.

MDA was found to have a significant positive relationship with the dimensions of emotional exhaustion and depersonalization, according to the findings of this study. Some research has been done in the past on the link between occupational burnout and oxidative stress, but none of those studies specifically addressed the link between MDA and burnout dimensions [1517, 55]. People with high levels of burnout, on the other hand, have higher levels of MDA, according to studies. Burnout occurs as a result of exposure to stressful situations [2], and stressful situations raise reactive oxygen levels $[15,16]$ which can lead to peroxide destruction of the cell's lipid membrane, resulting in $\operatorname{MDA}[21,22,56]$.

\section{Conclusion}

The findings of this study revealed that personal accomplishment is one of the most important factors influencing nurses' job burnout. Age, work experience, and neuroticism are also among the most important predictive variables of TAC levels. Marital status, employment status, working ward, emotional exhaustion, and depersonalization, on the other hand, were the most important predictor variables of MDA. TAC levels are highly influenced by personality factors, whereas MDA levels are primarily influenced by job burnout, according to this study. Given that MDA is one of the most important effective factors and TAC is one of the most important cancer-preventive factors, these elements should be highlighted, measured, and eliminated to avoid future negative health effects in the workplace. Healthcare organizations should consider programs like positive psychology training and coping techniques training for their employees to avoid potentially harmful consequences for vulnerable nurses.

\section{Limitations}

The impact on oxidative stress of some important factors, such as lifestyle and diet, was not considered in this study. Furthermore, some potential participants were excluded from this study due to the unclear effects of some factors, such as exposure to radioactivity and smoke, and the results of this study should not be overgeneralized to all nurses. The authors of this paper recommend that future studies be conducted on a larger number of nurses and those other variables affecting oxidative stress biomarkers be taken into account.

\section{Acknowledgments}

The Iran University of Medical Sciences, Tehran, Iran, provided support for this study under grant number 95-04-27-29995. The authors would like to thank everyone who took part in and helped with this study, as well as Shahroud University of Medical Sciences.

\section{Conflict of Interest}

The authors declare that they have no confilict of 
interest.

\section{References}

1. Wu S-Y, Li H-Y, Wang X-R, Yang S-J \& Qiu H (2011): A comparison of the effect of work stress on burnout and quality of life between female nurses and female doctors. Archives of Environmental \& Occupational Health 66 (4): 193-200

2. Maslach C \& Leiter MP (2017): New insights into burnout and health care: Strategies for improving civility and alleviating burnout. Medical Teacher 39 (2): $160-163$

3. Poghosyan L, Clarke SP, Finlayson M \& Aiken LH (2010): Nurse burnout and quality of care: Cross-national investigation in six countries. Research in Nursing \& Health 33 (4): 288-298

4. Sorour AS \& El-Maksoud MMA (2012): Relationship between musculoskeletal disorders, job demands, and burnout among emergency nurses. Advanced Emergency Nursing Journal 34 (3): 272-282

5. Boamah SA \& Laschinger H (2016): The influence of areas of worklife fit and work-life interference on burnout and turnover intentions among new graduate nurses. Journal of Nursing Management 24 (2): E164E174

6. Greco P, Laschinger HK \& Wong C (2006): Leader empowering behaviours, staff nurse empowerment and work engagement/burnout. Nurs Leadersh (Tor Ont) 19 (4): 41-56

7. Lee H-F, Yen M, Fetzer S \& Chien TW (2015): Predictors of burnout among nurses in Taiwan. Community Mental Health Journal 51 (6): 733-737

8. Pick D \& Leiter MP (1991): Nurses' perceptions of burnout: a comparison of self-reports and standardized measures. Can J Nurs Res 23 (3): 33-48

9. Maslach C, Schaufeli WB \& Leiter MP (2001): Job burnout. Annu Rev Psychol 52: 397-422

10. Hudek-Knezevic J, Kalebic Maglica B \& Krapic N (2011): Personality, organizational stress, and attitudes toward work as prospective predictors of professional burnout in hospital nurses. Croat Med J 52 (4): 538549

11. Fornés-Vives J, García-Banda G, Frías-Navarro D, Hermoso-Rodríguez E \& Santos-Abaunza P (2012): Stress and neuroticism in Spanish nursing students: A two-wave longitudinal study. Research in Nursing \& Health 35 (6): 589-597

12. Voltmer E, Kieschke U, Schwappach DLB, Wirsching M \& Spahn C (2008): Psychosocial health risk factors and resources of medical students and physicians: a cross-sectional study. BMC Medical Education 8 (1): 46

13. Cañadas-De la Fuente GA, Vargas C, San Luis C, Garcia I, Canadas GR \& De la Fuente EI (2015): Risk factors and prevalence of burnout syndrome in the nursing profession. Int J Nurs Stud 52 (1): 240-249

14. Ang SY, Dhaliwal SS, Ayre TC et al (2016): Demographics and personality factors associated with burnout among nurses in a Singapore Tertiary Hospital. BioMed Research International 2016: 6960184

15. Casado Á, De Lucas N, López-Fernández E, Sánchez A \& Jimenez J-A (2006): Lipid peroxidation, occupational stress and aging in workers of a prehospital emergency service. European Journal of Emergency Medicine 13 (3): 165-171

16. Casado Á, Castellanos A, López-Fernández ME, Ruíz R, García Aroca C \& Noriega F (2008): Relationship between oxidative and occupational stress and aging in nurses of an intensive care unit. AGE 30 (4): 229-236

17. Casado Á, Castellanos A, López-Fernández ME et al (2011): Determination of oxidative and occupational stress in palliative care workers. Clinical Chemistry and Laboratory Medicine 49 (3): 471-477

18. Dubey RK, Gautam N, Dhakal N, Baral N, Lamsal M \& Shyangwa PM (2015): Antioxidant enzyme activities and lipid peroxidation in patients with bipolar affective disorder. Journal of Universal College of Medical Sciences 3 (3): 12-16

19. Song J, Gao T, Ye M, Bi H \& Liu G (2012): The photocytotoxicity of different lights on mammalian cells in interior lighting system. J Photochem Photobiol B 117: $13-18$

20. Schumacker PT (2015): Reactive oxygen species in cancer: a dance with the devil. Cancer Cell 27 (2): $156-157$

21. Schieber M \& Chandel NS (2014): ROS function in redox signaling and oxidative stress. Curr Biol 24 (10): R453-462

22. Tong L, Chuang CC, Wu S \& Zuo L (2015): Reactive oxygen species in redox cancer therapy. Cancer Lett 367 (1): 18-25 
23. Karaaslan C \& Suzen S (2015): Antioxidant properties of melatonin and its potential action in diseases. Curr Top Med Chem 15 (9): 894-903

24. Shukla V, Mishra SK \& Pant HC (2011): Oxidative stress in neurodegeneration. Adv Pharmacol Sci 2011: 572634

25. Siti HN, Kamisah Y \& Kamsiah J (2015): The role of oxidative stress, antioxidants and vascular inflammation in cardiovascular disease (a review). Vascul Pharmacol 71: 40-56

26. Tangvarasittichai S (2015): Oxidative stress, insulin resistance, dyslipidemia and type 2 diabetes mellitus. World J Diabetes 6 (3): 456-480

27. Haigis MC \& Yankner BA (2010): The aging stress response. Mol Cell 40 (2): 333-344

28. Bello Hu, Dandare A \& Danmaliki G (2017): Effects of cigarette smoking on lipid peroxidation and serum antioxidant vitamins. IOSR Journal of Pharmacy and Biological Sciences 12: 40-44

29. Szumiel I (2015): Ionizing radiation-induced oxidative stress, epigenetic changes and genomic instability: the pivotal role of mitochondria. Int J Radiat Biol 91 (1): $1-12$

30. Conklin KA (2004): Cancer chemotherapy and antioxidants. J Nutr 134 (11): 3201S-3204S

31. Chari MG \& Colagar AH (2011): Seminal plasma lipid peroxidation, total antioxidant capacity, and cigarette smoking in asthenoteratospermic men. Journal of Men's Health 8 (1): 43-49

32. Lorenz VR, Benatti MCC \& Sabino MO (2010): Burnout and stress among nurses in a university tertiary hospital. Revista Latino-Americana de Enfermagem 18 (6): 1084-1091

33. Filian E(1992): Survey of relationship between Job burnout and transfer check styles in nurses. Tarbiat ModaresTehran:35-45 (in Persian)

34. Costa TP, Jr. (1992): The NEO-PI-R professional manual : Revised NEO Five-Factor Inventory. (NEO-FFI). Psychological Assessment Resources, FL 101pp

35. Ghanei Gheshlagh R, Valiei S, Rezaei M \& Rezaei K (2013): The relationship between personality characteristics and Nursing occupational stress. Journal of Nursing Education 1 (3): 27-34

36. Hayes B, Douglas C \& Bonner A (2015): Work environment, job satisfaction, stress and burnout among haemodialysis nurses. Journal of Nursing Manage- ment 23 (5): 588-598

37. De la Fuente-Solana EI, Gómez-Urquiza JL, Cañadas GR, Albendín-García L, Ortega-Campos E \& CañadasDe la Fuente GA (2017): Burnout and its relationship with personality factors in oncology nurses. European Journal of Oncology Nursing 30: 91-96

38. Jahanbakhsh Ganjeh S, Omidi Arjenaki N, Nouri AA \& Oreyzi Samani SHR (2009): The relationship of personality characteristics and burnout among nurses. Iranian Journal of Nursing and Midwifery Research (IJNMR) 14 (4): 190-194

39. Geuens N, Van Bogaert P \& Franck E (2017): Vulnerability to burnout within the nursing workforce-The role of personality and interpersonal behaviour. Journal of Clinical Nursing 26 (23-24): 4622-4633

40. Nater UM, Hoppmann C \& Klumb PL (2010): Neuroticism and conscientiousness are associated with cortisol diurnal profiles in adults-Role of positive and negative affect. Psychoneuroendocrinology 35 (10): 15731577

41. Demirbag R, Yilmaz R \& Erel O (2005): The association of total antioxidant capacity with sex hormones. Scandinavian Cardiovascular Journal 39 (3): 172-176

42. Jones DP, Mody VC, Carlson JL, Lynn MJ \& Sternberg $P$ (2002): Redox analysis of human plasma allows separation of pro-oxidant events of aging from decline in antioxidant defenses. Free Radical Biology and Medicine 33 (9): 1290-1300

43. Sharifian A, Farahani S, Pasalar P, Gharavi M \& Aminian O (2005): Shift work as an oxidative stressor. Journal of Circadian Rhythms 3 (1): 15

44. Ranjbar A, Barkhordari A, Dehghani A, Mehrparvar Ah \& Keshvari Shad M (2016): The study of oxidative stress biomarkers in ceramic workers compared to control group. Occupational Medicine Quarterly Journal 7 (4): 67-81 (in Persian)

45. Lee H-C, Chang C-M \& Chi C-W (2010): Somatic mutations of mitochondrial DNA in aging and cancer progression. Ageing Research Reviews 9: S47-S58

46. Suresh D, Kumaran S, Annam V \& Veena H (2010): Age related changes in malondialdehyde: Total antioxidant capacity ratio - A novel marker of oxidative stress. International Journal of Pharma and Bio Sciences V1(2):1-6

47. Costa Jr. PT \& McCrae RR (1987): Neuroticism, somatic complaints, and disease: Is the bark worse than 
the bite? Journal of Personality 55 (2): 299-316

48. Appel S, Chapman J \& Shoenfeld Y (2007): Infection and vaccination in chronic fatigue syndrome: Myth or reality? Autoimmunity 40 (1): 48-53

49. Matsushita M, Kumano-Go $\mathrm{T}$, Suganuma $\mathrm{N}$ et al (2010): Anxiety, neuroticism and oxidative stress: Cross-sectional study in non-smoking college students. Psychiatry and Clinical Neurosciences 64 (4): 435-441

50. Casado Á, López-Fernández E \& Castellanos A (2014): Physical exercise reduces occupational and oxidative stress in Emergency Department staff. Revista del Laboratorio Clínico 7 (3): 96-103 (In Spanish)

51. Moshtagh Eshgh Z, Aghaeinezhad Aa, Peyman A, Amirkhani A, Taghinejad F \& Sheikhi Aa (2014): The relationship between occupational stresses with job burnout in pre-hospital emergency staff. Jorjani Biomedicine Journal 2 (2): 41-33

52. López Franco M, Rodríguez Núñez A, Fernández Sanmartín M, Marcos Alonso S, Martinón Torres F \& Martinón Sánchez JM (2005): Burnout syndrome among health workers in pediatrics. An Pediatr (Barc) 62 (3): 248-251 (In Spanish)

53. Mehafarid M, Khakpour M, Jajarmi M \& Alizadeh mousavi A (2015): Effectiveness of positive thinking training on hardiness $\&$ resilience and Job burnout in women nurses. Journal of Nursing Education 4 (1): $72-83$

54. Zhang L-f, You L-m, Liu K et al (2014): The association of Chinese hospital work environment with nurse burnout, job satisfaction, and intention to leave. Nursing Outlook 62 (2): 128-137

55. Grossi G, Perski A, Evengård B, Blomkvist V \& OrthGomér K (2003): Physiological correlates of burnout among women. Journal of Psychosomatic Research 55 (4): 309-316

56. Ray PD, Huang B-W \& Tsuji Y (2012): Reactive oxygen species (ROS) homeostasis and redox regulation in cellular signaling. Cellular Signalling 24 (5): 981-990

J UOEH $43(4): 397-408(2021)$ 